\title{
Un nuevo conjunto epigráfico en el foro romano de Los Bañales (Uncastillo, Zaragoza)*
}

\section{On a new epigraphic monument in the Roman forum of Los Bañales (Uncastillo, Zaragoza)}

\author{
Ángel A. Jordán Lorenzo \\ Archivo Epigráfico de Hispania \\ Javier Andreu Pintado \\ Universidad Nacional de Educación a Distancia - UNED
}

\section{RESUMEN}

El presente trabajo da noticia de cinco nuevas inscripciones descubiertas in situ en uno de los recintos, de naturaleza cultual y autorepresentativa, en los que se abría el pórtico occidental del foro de la ciudad romana de Los Bañales (Uncastillo, Zaragoza) un municipio del antiguo conuentus Caesaraugustanus de la Tarraconense. El conjunto, de carácter dinástico y promovido por M. Fabius Nouus y Porcia Faventina, se articuló en torno a una dedicatoria a la Victoria Aug(usta) y a una serie de homenajes cruzados a miembros de las familias de los dedicantes, hasta la fecha prácticamente desconocidas en la prosopografía de la citada comunidad, de nombre antiguo aun ignoto.

\section{SUMMARY}

The following paper presents five new Roman inscriptions discovered in situ in one of the enclosures in which the occidental porticus of the forum of the Roman city of Los Bañales (Uncastillo, Zaragoza) — conventus Caesaraugustanus of Hispania Citerior - was opened probably for cultural an self-representation purposes. The monument, of a dynastic and familiar character, was promoted by M. Fabius Nouus and Porcia Faventina and was articulated surrounding a main dedication to the Victoria Aug(usta) and a series of crossed tributes to members of both families, with names that remain unattested in the local prosopography of the aforementioned community whose ancient name is unknown to this day.

${ }^{*}$ El presente trabajo se integra en las actividades del Plan de Investigación que - por encargo y financiación de la Dirección General de Patrimonio Cultural del Departamento de Educación, Cultura y Deporte del Gobierno de Aragón y la dirección de la Fundación Uncastillo- se viene llevando a cabo en el yacimiento arqueológico romano de Los Bañales (Uncastillo, Zaragoza) (http://www.losbanales.es). El contenido del mismo se ha visto notablemente enriquecido por las indicaciones de los informantes y evaluadores anónimos de la revista que acoge este estudio, vaya para ellos nuestra pública manifestación de gratitud.
PALABRAS CLAVES: Los Bañales, elites locales, foros, auto-representación, conjuntos dinásticos, culto imperial, Victoria.

KEY WORDS: Los Bañales, local elite, forum, self-representation, dinastic monuments, imperial cult, Victoria.

\section{INTRODUCCIÓN}

Los Bañales (Uncastillo, Zaragoza) es el nombre con el que se conoce popularmente a los restos de una ciudad romana — de nombre antiguo aun ignoto (véase, para las opciones Andreu 2011: 30-31) — emplazada en la actual Comarca de las Cinco Villas, al pie de una calzada estratégica que permitía la unión de Caesaraugusta con el Sur de la Galia y el Cantábrico (Aguarod y Lostal 1982; Magallón 1986; Moreno 2009). La ciudad se extiende a lo largo de 24 ha. en la parte central de un valle regado por los ríos Riguel — al oeste — y Arba de Luesia —al este- y comprendido entre los cerros de El Pueyo, al oeste, Puy Foradado, al este, y El Huso y La Rueca, al sur, mientras que al norte limita con el barranco de Valdebañales (Andreu et alii 2008). En este espacio y, más en concreto, en la ladera este de El Pueyo, la Fundación Uncastillo, por encargo de la Dirección General de Patrimonio del Gobierno de Aragón, viene realizando desde hace cinco años excavaciones arqueológicas en dos zonas correspondientes a un barrio doméstico-artesanal, situado en las inmediaciones de un pequeño recinto termal (Uribe et alii 2011: 253-260; Andreu 2012: 56-61; 2013), y al foro de la ciudad (Andreu 2012: 44-48; Andreu et alii e. p.). 


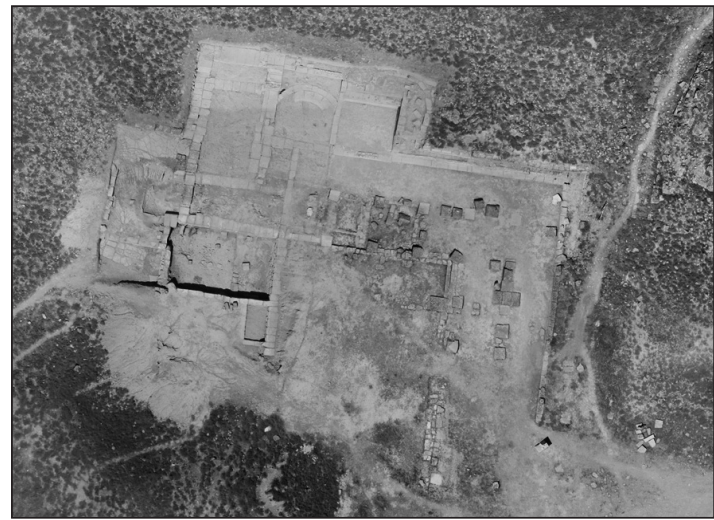

Figura 1. Helifoto del pórtico occidental del foro de Los Bañales (Uncastillo) (Foto: 3DScanner Patrimonio e Industria).

Los trabajos en este último espacio se han centrado en su pórtico oeste descubriéndose, a lo largo de las campañas de 2011, 2012 y 2013, la existencia en él de hasta cuatro recintos, tres con cabecera recta y uno con cabecera curva, al menos en su fase final y que, posiblemente, tuvieron carácter sacro y función, también, auto-representativa de las familias que promovieron y financiaron al menos dos de ellos (Fig. 1). Esos dos, precisamente, la exedra y el recinto ubicado a su derecha, han permitido recuperar un impresionante conjunto de hasta nueve inscripciones in situ, cuatro en la exedra (Jordán 2012) y cinco en el recinto que nos ocupa, centrándose la atención en las siguientes páginas, en este último espacio, el de más reciente excavación y, probablemente, el más espectacular de los dos dado su excelente estado de conservación.

\section{EL CONTEXTO ARQUEOLÓGICO}

El recinto que se presenta a continuación corresponde a una habitación de planta cuadrada de 5,34 x 4,70 m, que se abre al pórtico occidental del foro de la ciudad (Fig. 2). Para su construcción se emplearon grandes sillares de piedra arenisca local dispuestos a hueso, con la peculiaridad de que, en el caso del muro

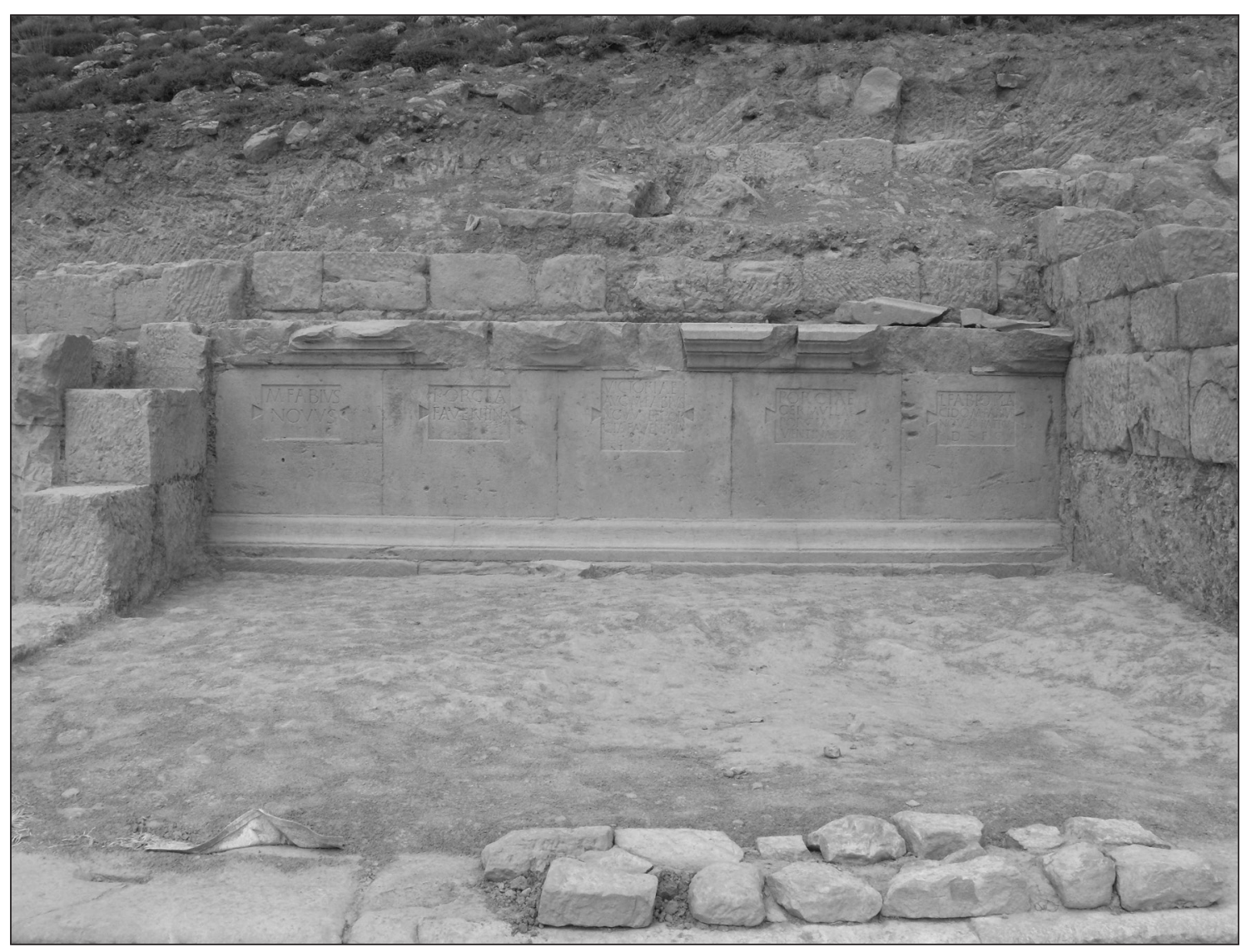

Figura 2. Recinto derecho del pórtico occidental (Foto: Á. A. Jordán). 


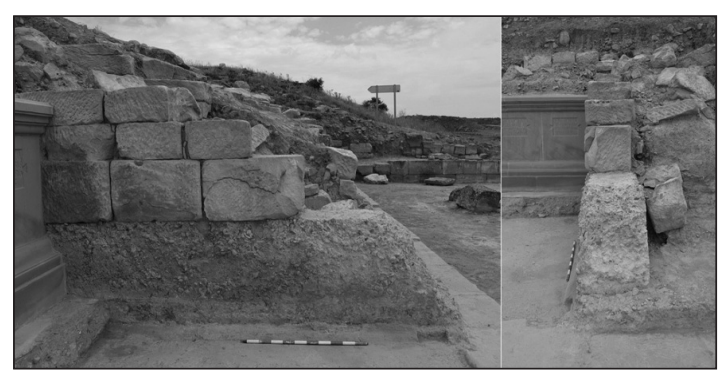

Figura 3. Muro norte de la edícula (Fotos: Á. A. Jordán).

norte, se asentaron sobre una gruesa cimentación de hormigón de $67 \mathrm{~cm}$ de altura y $50 \mathrm{~cm}$ de grosor (Fig. 3).
Este tipo de construcción mixta no es extraña en el mundo romano (Giuliani 1997), si bien es cierto que suele ser más frecuente emplear el hormigón en el núcleo de las paredes para después revestirlo con lajas de piedra o mármol o simplemente revocarlo con argamasa como, posiblemente, fue el caso del edificio que nos ocupa. En relación con ello y al margen de la función estructural del hormigón, cabe destacar el relleno de uno de los sillares del muro sur con hormigón, con la finalidad de obtener una superficie homogénea sobre la cual enlucir, así como pequeños restos de este enlucido recuperados en las excavaciones (Figs. 4 y 5). Además, la investigación arqueológica de este recinto ha permitido identificar

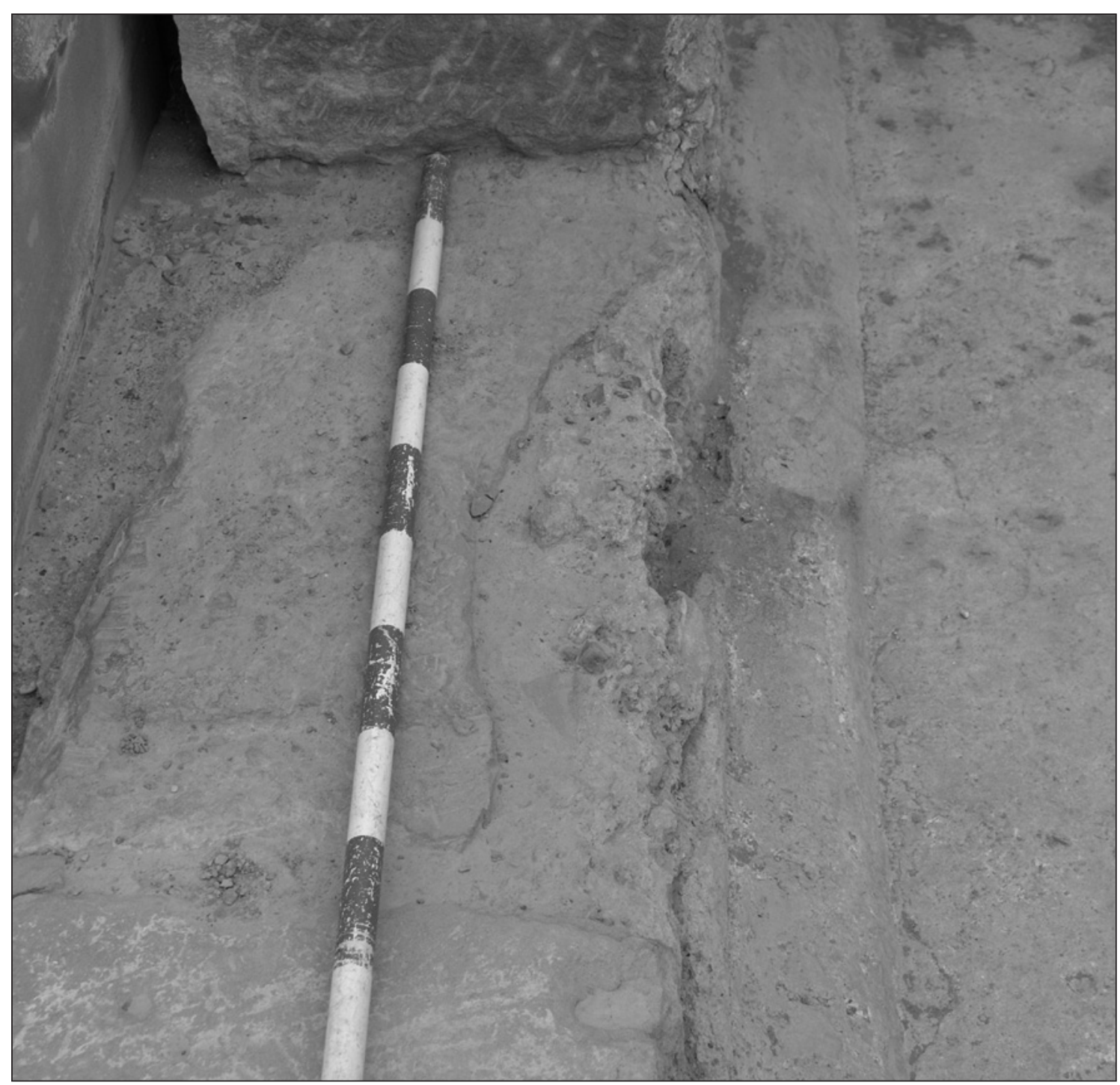

Figura 4. Detalle del muro sur de la edícula, con un sillar fragmentado y rellenado con hormigón (Foto: Á. A. Jordán). 


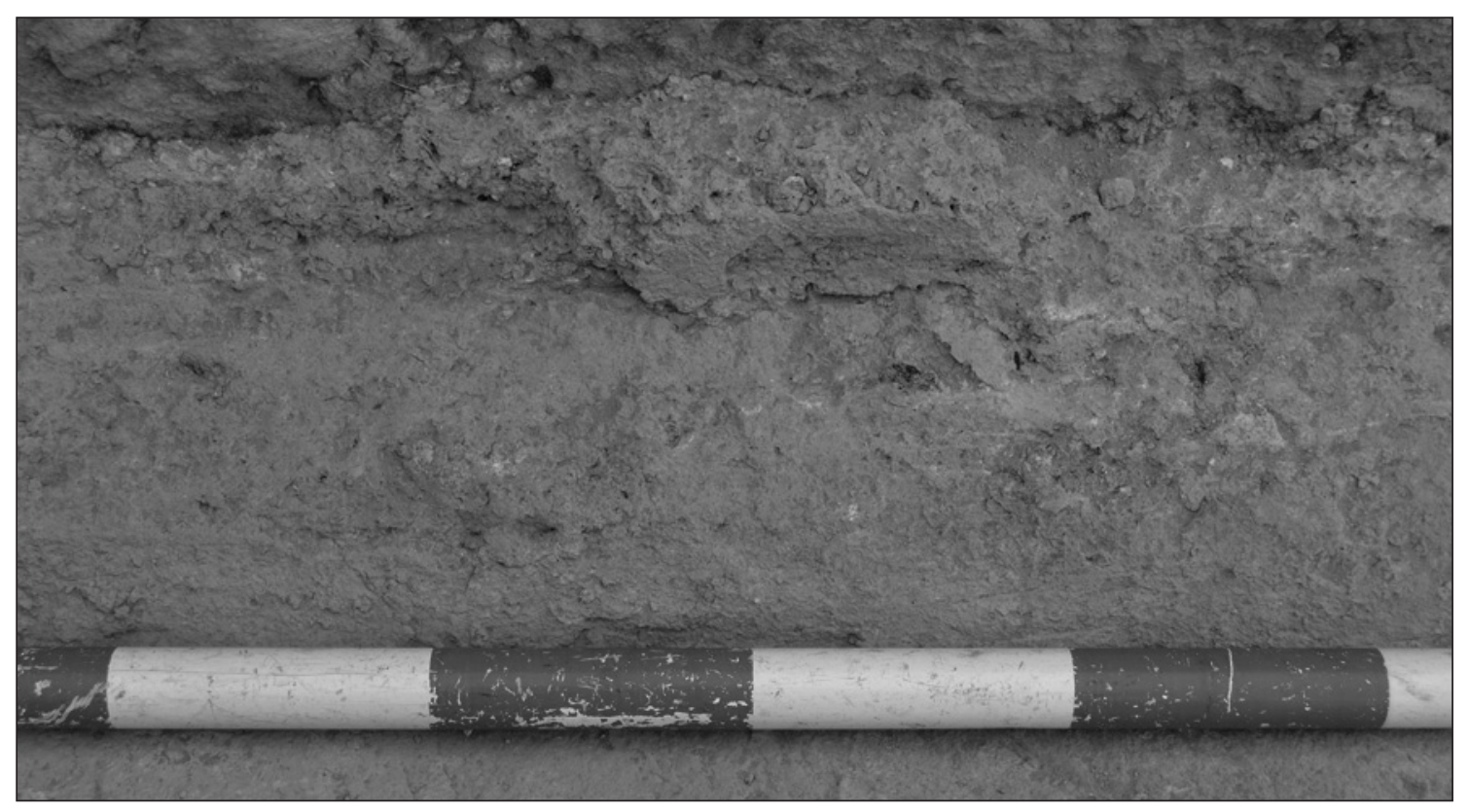

Figura 5. Resto conservado en el muro norte del enlucido de la pared del recinto (Foto: Á. A. Jordán).

una pequeña caída de pinturas, en su mayoría fragmentos blancos con algún filete rojo, y un zócalo de estuco blanco en su lado este.

En la pared que cerraba el acceso al pórtico se han conservado tres marcas de anclaje que, posiblemente, permitían la disposición de una reja (Fig. 6). Esto permite inferir que se trataría de un espacio cerrado al público, aunque visualmente abierto. La puerta fue clausurada con posterioridad por un muro de sillarejo de $240 \mathrm{~cm}$ x $40 \mathrm{~cm}$, lo cual, quizá, facilitó la conservación de este conjunto.

Por último, el suelo estaba recubierto por un pavimento de opus signinum flanqueado por dos gruesos baquetones realizados en opus caementicium, dispuestos en el ángulo entre el suelo y la pared. En uno de ellos, el derecho, se conserva la cuna para una viga rectangular de 25 × $8 \mathrm{~cm}$ que, posiblemente, sirvió para sustento del dintel que permitiría abrir el vano de entrada. El conjunto de sujeción de este dintel se completaba con una segunda viga de similares dimensiones, dispuesta en perpendicular a la anterior, cuya cuna se conserva labrada en el sillar (Fig. 7). Además, este pavimento de opus signinum muestra un considerable grado de desgaste en la entrada al recinto, así como hacia ambos costados: en dirección al conjunto epigráfico de los promotores del recinto y a la inscripción n. 5. Por el contrario, por el centro del conjunto epigráfico dicho desgaste se aprecia como menor, diferencia quizá producida por la existencia de algún objeto móvil que impediría el paso (Fig. 8).

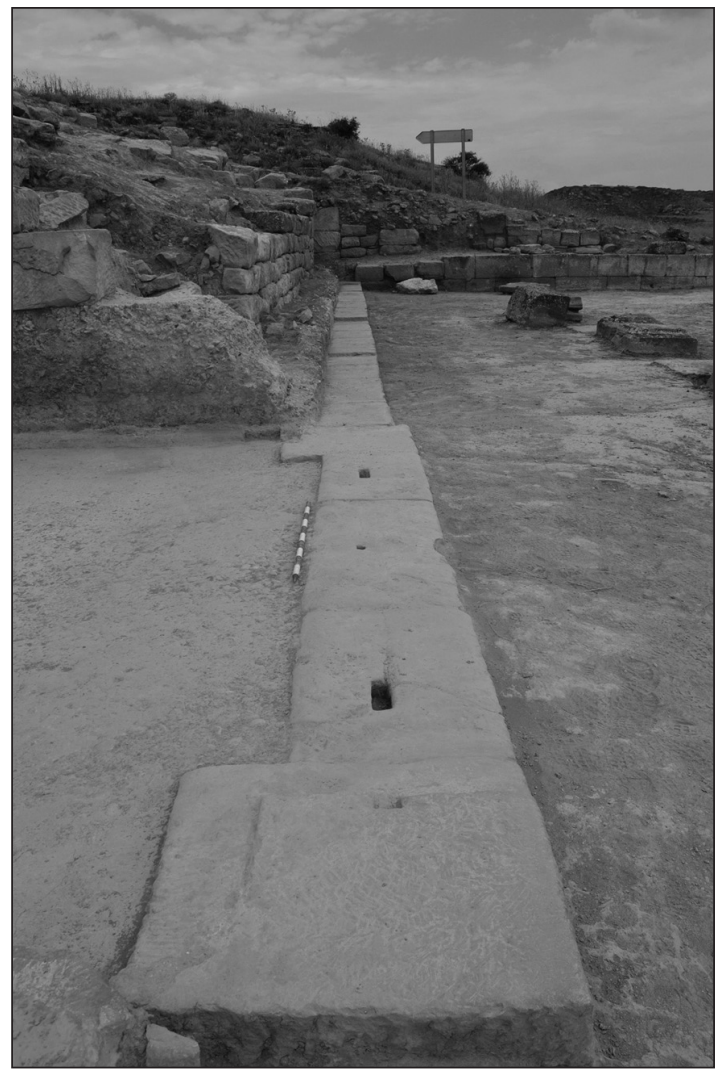

Figura 6. Cunas para el posicionamiento de la reja de acceso a la edícula (Foto: Á. A. Jordán). 


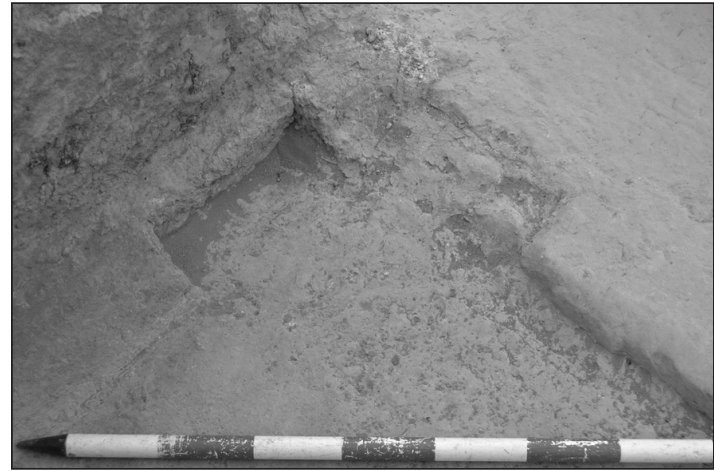

Figura 7. Detalle de las cunas para vigas (Foto: Á. A. Jordán).

La excavación de este espacio permitió recuperar un conjunto de restos óseos humanos bajo una caída de piedras, sin materiales asociados. El cadáver estaba dispuesto de forma totalmente flexionada sobre sí mismo y con la extremidad superior derecha sobre la cabeza y la izquierda sobre el cuerpo (Fig. 9), sobre el nivel ya de cierre y abandono de esta estructura. A $20 \mathrm{~cm}$ del suelo de opus signinum se localizó el primer nivel de deposición en este espacio, quizá previo a su tapiado, caracterizado por la identificación de un vertido de cenizas junto al muro norte (Fig. 10). Entre ellas se recuperaron abundante restos de cerámica de almacenaje, un clavo y un fragmento de cerámica, posiblemente terra sigillata hispánica tardía de muy buena calidad (Fig. 11). El hallazgo de este pequeño fragmento permite situar este vertido $y$, por extensión, el abandono del conjunto y su posterior tapiado, en un momento incierto comprendido entre los siglos III-VI d.C.

Junto a estos materiales, en el resto del recinto se han localizado diferentes fragmentos cerámicos fruto

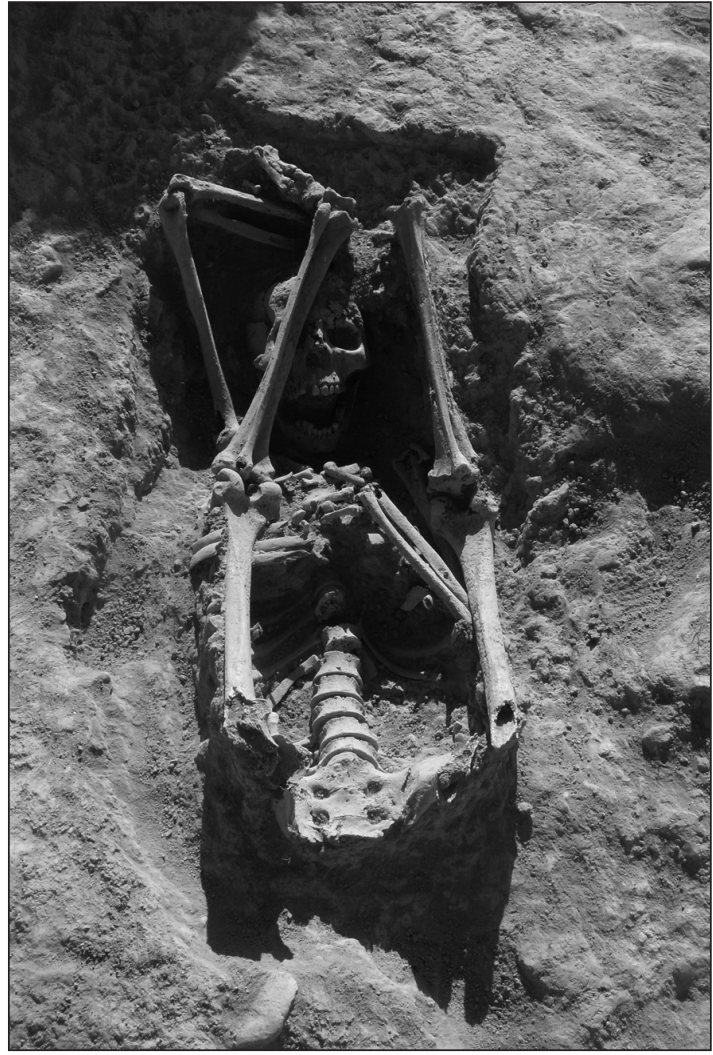

Figura 9. Restos óseos humanos localizados sobre el nivel de abandono del recinto (Foto: Á. A. Jordán).

del abandono y acumulación paulatinas. Entre ellos destacan fragmentos de tegulae e imbrices, un clavo partido en dos, algunos pequeños huesos y abundantes fragmentos de cerámica romana de almacenaje (Fig. 12).

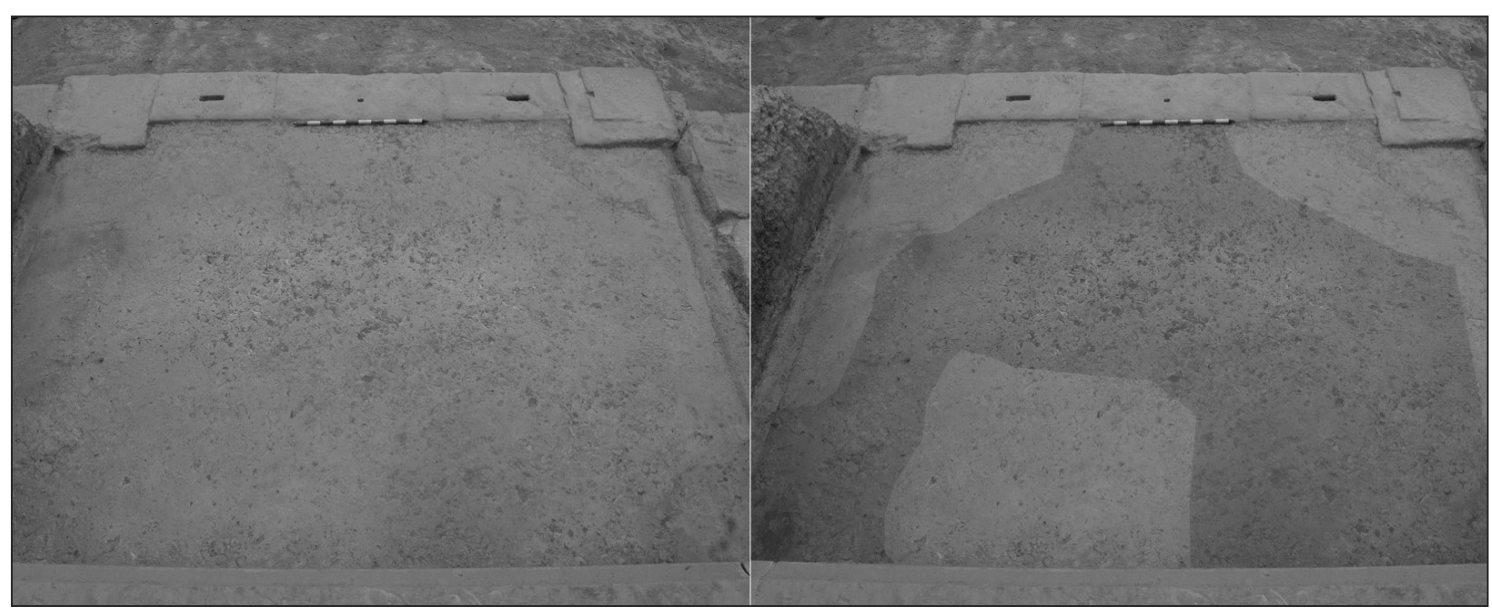

Figura 8. Pavimento de la edícula. A la derecha, resaltado, superficie de mayor desgaste (Foto: Á. A. Jordán). 


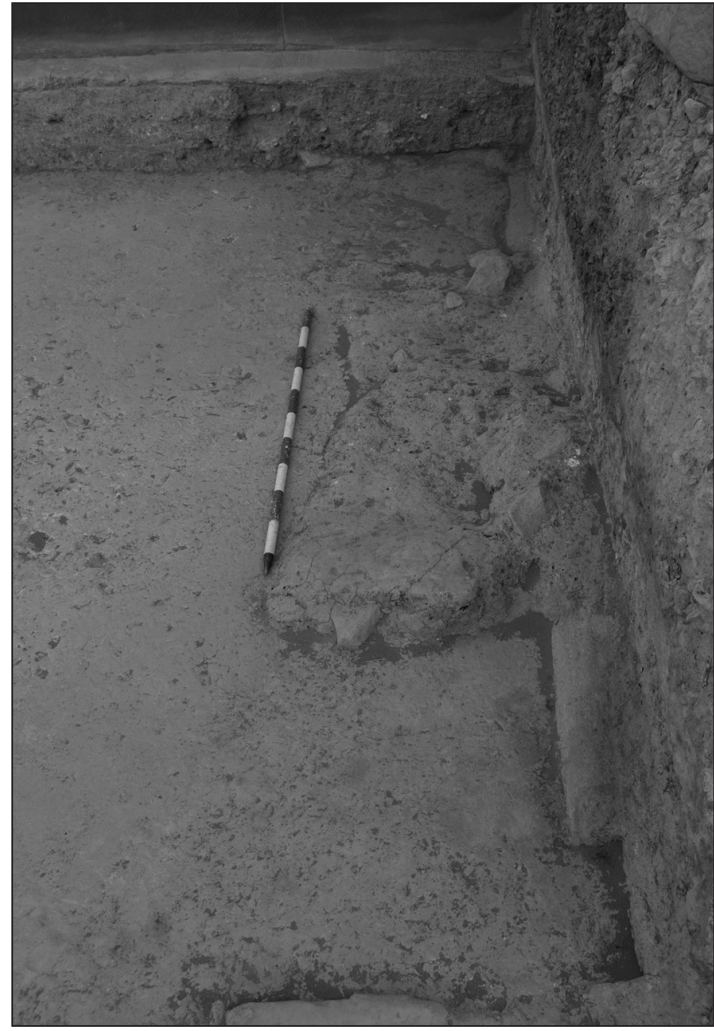

Figura 10. Depósito de cenizas tardío contra el muro norte (Foto: Á. A. Jordán) probando el abandono del recinto (Foto: Á. A. Jordán).

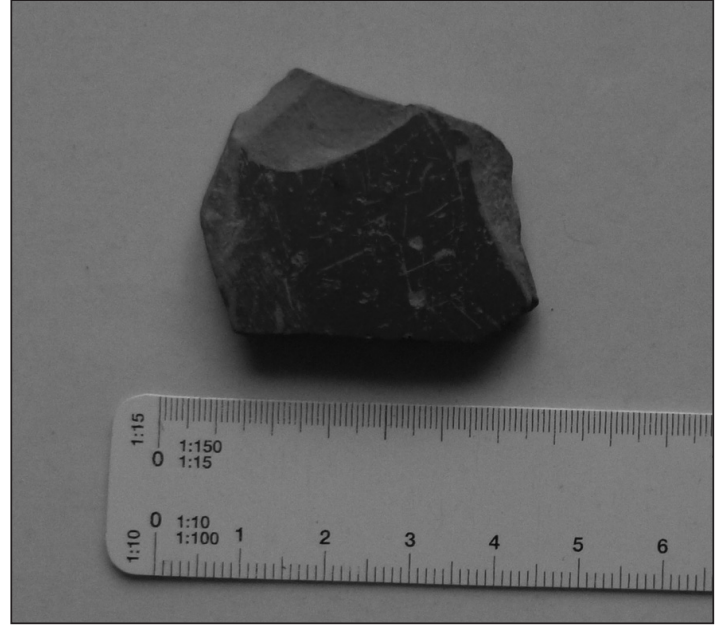

Figura 11. Posible fragmento de TSHT encontrado en el depósito de cenizas (Foto: Á. A. Jordán).

\section{EL CONJUNTO EPIGRÁFICO}

En este esquema constructivo, las cinco inscripciones conservadas se dispusieron en el muro del fondo, de frente a la puerta de acceso, formando un podio corrido con zócalo y cornisa (Fig. 2). El zócalo está asentado sobre una hilera de sillares y aparece moldurado $(18 \times 11 \mathrm{~cm})$, con una secuencia de talón invertido $(7 \times 6 \mathrm{~cm})$ y escocia $(10 \times 5 \mathrm{~cm})$ para terminar con un pequeño listel $(1 \times 2 \mathrm{~cm})$. Sobre él

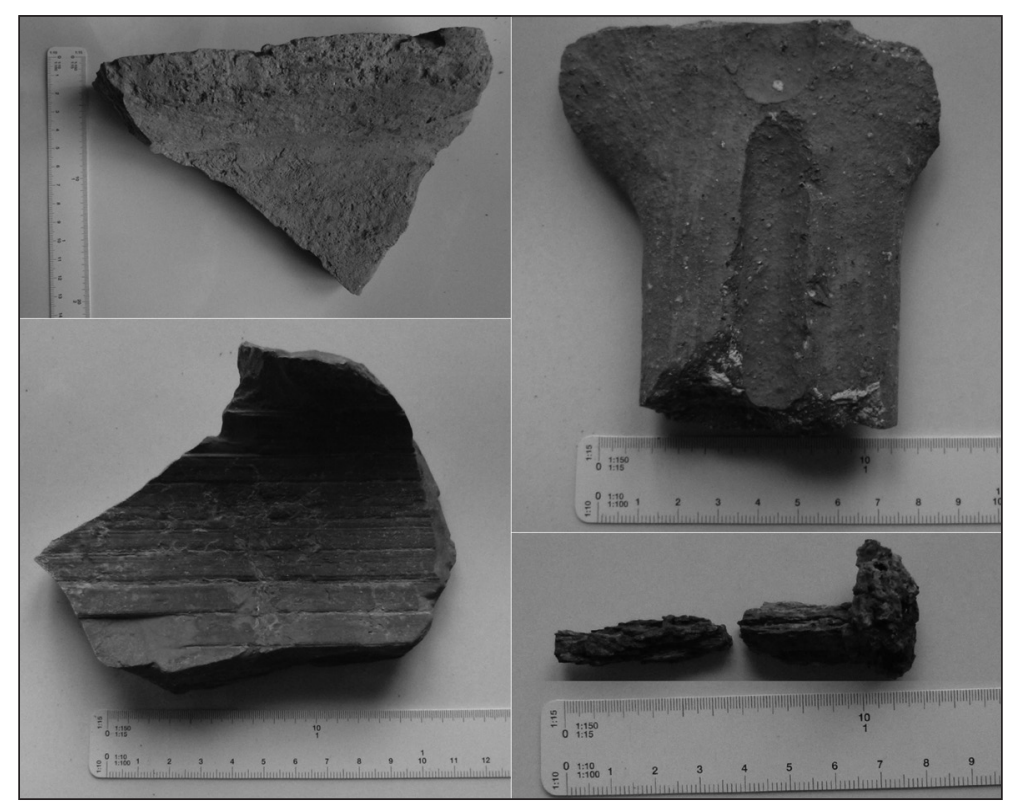

Figura 12. Restos materiales hallados durante la excavación de la edícula (Foto: Á. A. Jordán). 
se asienta el cuerpo del monumento, formado por bloques o placas de arenisca de 82 × $97 \mathrm{~cm}$ de media, para terminar con una cornisa corrida, también moldurada, de 26,5 x $77 \mathrm{~cm}$, sobre la cual se conservan las cunas de anclaje de las estatuas que completarían el conjunto hoy protegido por unas réplicas para facilitar su conservación in situ. Los textos, todos ellos inscritos en el interior de un campo epigráfico en forma de tabula ansata - motivo epigráfico especialmente bien atestiguado en la documentación epigráfica de la comarca (Jordán 2009: 522)— son los siguientes:

1. Medidas: 81,5 x 97 x? Campo epigráfico: 29 x 45. Letras: 8-7,5. Capital cuadrada. Interpunción triangular (Fig. 13).

M(arcus) $)$ Fabius

Nouus

Se conocen otros dos testimonios de Fabii en las cercanías de Los Bañales. Así, por ejemplo, E. Hübner da la noticia de la existencia de una inscripción perdida donde aparece una Fabia Ederettatia C. Irurciradin (filia) (?), in domo Balthasaris de Arbués, en Sádaba, hoy perdida. Además, de Layana procede otro texto -también desaparecido- donde figuran sendas Fabiae $^{1}$. Por su parte, Nouus es un cognomen poco extendido en la epigrafía peninsular. Está formado a partir de un adjetivo (Kajanto 1965: 71).

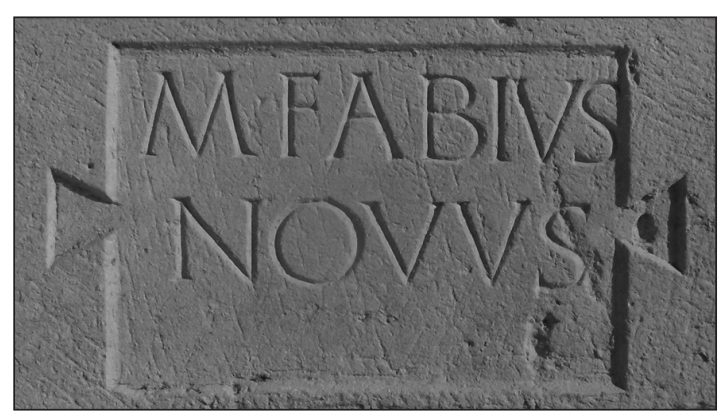

Figura 13. Inscripción no 1 (Foto: Á. A. Jordán).

2. Medidas: 81,5 x 98 x ? Campo epigráfico: 29 x 45,5. Letras: 7,5-4. Capital cuadrada (Fig. 14).

Porcia

Fauentina

\footnotetext{
${ }^{1}$ CIL II 2976 = ERZ 27, cf. Andreu y Jordán 2003-2004, n. 9: C(aius) Plotius C(ai) filius Siaco / h(ic) s(itus) e(st) / Fabia Ederetta/tia C(ai) Irurciradin (filia); CIL II 2977 = ERZ 24, cf. Andreu y Jordán 2003-2004, n. 8: --- ? / Fabia filia hic iacet / [---] ann(orum) XXVI [---/ ---] et etiam [--- / ---] Fabia mater. Nota: para las abreviaturas de los corpora epigráficos se siguen las presentadas en el listado comúnmente admitido de la base de datos de Clauss-Slaby (www.manfredclauss.de). Para el gentilicio Fabius véase Abascal 1994: 132-136 y Solin y Salomies 1994: 76.
}

En lín. 2, la última $A$ se grabó en un tamaño mucho menor, $4 \mathrm{~cm}$, por un probable error del artesano en la ordinatio. El nomen Porcius (Abascal 1994: 203-205) no está muy extendido en el conuentus Caesaraugustanus, aunque, en la zona, es fácil su relación con el Segiensis Porcius Birrus, alfarero que debió de producir en Vareia ${ }^{2}$. Además, de la cercana localidad navarra de Carcastillo procede la estela de Porcius Felix, originario de Cara, municipio flavio posiblemente limítrofe con el de Los Bañales (Andreu 2014). El cognomen Fauentina está formado a partir del topónimo Fauentia, conociéndose, por el momento, otras quince atestiguaciones en la Península, ninguna, en cualquier caso, en el conuentus de Caesaraugusta (Abascal 1994: 35).

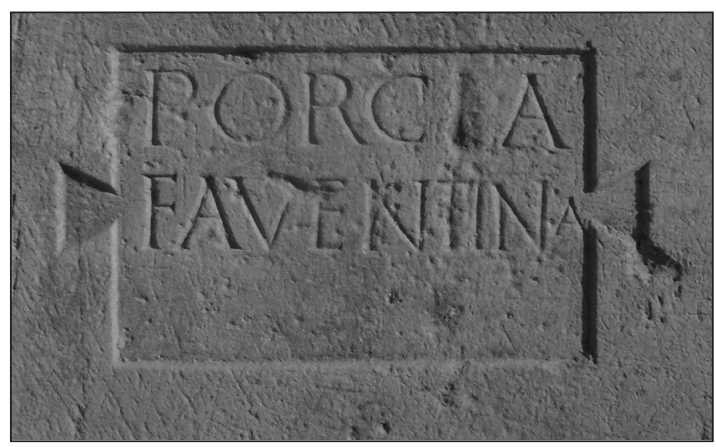

Figura 14. Inscripción nº 2 (Foto: Á. A. Jordán).

3. Medidas: 82 x 97 x? Campo epigráfico: 39,5 x 46,5. Letras: 6,5-6. Capital cuadrada. Interpunción triangular (Fig. 15).

Victoriae

Aug (ustae) $\cdot$ M(arcus) $\cdot$ Fabius

Nouus $\cdot$ et $\cdot$ Por

cia $\cdot$ Fauentina

${ }^{5} s($ ua $) \cdot p($ ecunia $) \cdot f($ ecerunt $)$

En lín. 5, las letras muestran un grado de desgaste considerablemente mayor que en el resto de líneas. En general, no aparecen demasiadas atestiguaciones del culto a la Victoria en las provincias peninsulares, puesto que, por el momento, se conocen treinta y

\footnotetext{
${ }^{2}$ AE 1991, $1063=$ HEp 4, 595j. Por el momento, se conocen otros nueve testimonios además del de Porcius Birrus, cf. CIL II 2962 = IRMN 39: Porcius Felixs de Carcastillo (Navarra), CIL II $3010=$ IRC II, 2: Porcia P. f. Nigrina de Ilerda, CIL II 5829: Porcia Ambata Segonti filia de Gastiain (Navarra), ERTeruel 6: Porc[ius, - $a$---] de Alcañiz (Teruel), HEp 6, 911: G. Porc[ius ---] de Cella (Teruel), HEp 1, 359: L. [Po]rcius Liberalis y Porcius Fuscus de Castellar (Huesca) y HEp 8, 562 = ERZ 17: L. Porcius Se[---] y L. Porcius [---] ternus de Chiprana (Zaragoza), a los que se puede sumar las noticias monetales del duunviro M. Porcius procedentes de Caesaraugusta (RPC n. 314-316).
} 


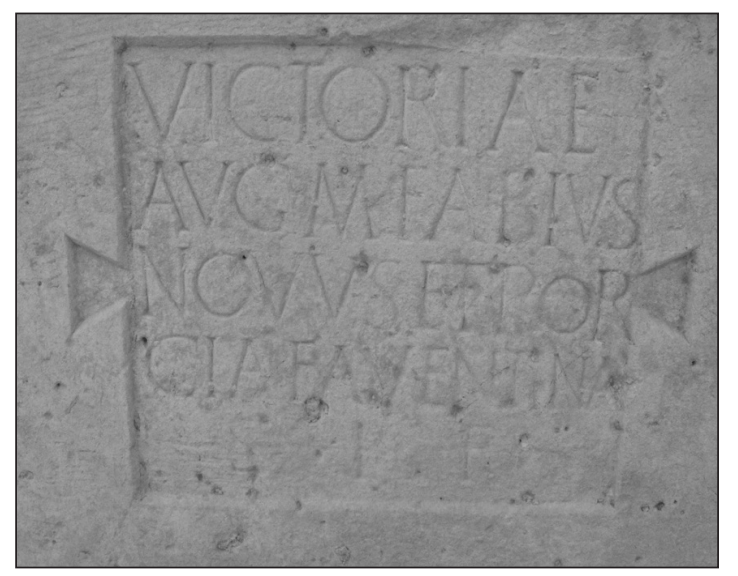

Figura 15. Inscripción nº 3 (Foto: Á. A. Jordán).

dos inscripciones, recogidas en las siguientes tablas donde éstas son presentadas por orden cronológico y agrupadas por provincias (Figs. 16, 17 y 18).

Como se puede apreciar, si bien el primer testimonio conservado de culto a la Victoria se data ya en época de Augusto, no va a ser hasta avanzado el Principado, a partir de mediados del siglo i d.C. y, sobre todo, del siglo II d.C., cuando se realicen la mayor parte de las dedicatorias conservadas. Estas tienden a concentrarse en dos grupos. El primero aparece representado por sencillas consagraciones a la Victoria, normalmente sin apelativo, y estas se concentran sobre todo en el conventus Emeritensis. A consecuencia de esta distribución geográfica tan reducida se ha planteado que tras ellos se oculta una realidad indígena prerromana aunque, por el momento, se desconoce cuál (Fernandes 2002: 169; Olteanu 2008: 207-209).

Por otro lado, el segundo grupo, dentro del cual se puede encuadrar el testimonio de Los Bañales, está protagonizado por consagraciones a la Victoria Aug., y se extiende sobre todo por el Levante Peninsular y la provincia Baetica. Con respecto a ellas, se ha planteado que se trate de una expresión de la felicitas imperial, así como de un aval para la sucesión en el trono, que se uniría a la idea de la invencibilidad del emperador romano (Fishwick 1987: 115-116). En las provincias, su culto acabó convirtiéndose en una manifestación más del culto al emperador: se trataría de la Victoria del Emperador, reconociendo su valía militar como el elemento fundador del Imperio. Es, a través de ella, como el Imperio se constituiría y se perpetuaría, encontrando en el desarrollo de las ciudades su mejor expresión (Etienne 1958: 326-327; Perea 2007: 228 y esp. 232). Se trata, en este contexto urbano y provincial, de una manifestación de la celebración del desarrollo urbano, bien físico (promoción jurídica de la ciuitas) o bien personal (adquisición de la ciudadanía), ámbito ideológico este en el que, como veremos, pudo moverse la dedicatoria y el conjunto que nos ocupan.

4. Medidas: 82 x 96 x? Campo epigráfico: 30 x 45. Letras: 6,5-4,5. Capital cuadrada. Interpunción triangular (Fig. 19)

Porciae

Germullae

Porcia $\cdot \mathrm{Fa}$

uentina $\cdot d($ e) $s($ uo $) \cdot f($ aciendum $) c($ urauit $)$

\begin{tabular}{|c|c|c|c|c|}
\hline Referencia & Lugar & Teónimo & Promotor & Cronología \\
\hline RIT $58=\underset{864}{\text { CIL II }{ }^{2} / 14,}$ & Tarraco & [Vi]ctor[ia A]ugusta & $\begin{array}{l}\text { [Colon]ia Triu[mphalis } \\
\text { Tarrac(onensium)] }\end{array}$ & Augusto \\
\hline $\begin{array}{c}\text { CIL II 5761 }=\text { IRPP } \\
12\end{array}$ & Pallantia & Victoria Augusti & T. Calpurnius Fronto & Siglo I d.C. \\
\hline IRC II, 21 & Aeso & Victoria Augusta & Aemilia Paterna & Siglos I-II d.C. \\
\hline $\begin{array}{c}\text { CIL II } 3410= \\
\text { Abascal y Ramallo } \\
\text { 1997, } \mathbf{n}^{\circ} 39\end{array}$ & Carthago Noua & Victoria Aug(usti) & C. Valerius Felix & Siglos I-II d.C. \\
\hline $\begin{array}{c}\text { CIL II } 3249=\text { CILA } \\
\text { III, } 45\end{array}$ & Baesucci & Victoria Aug(usti) & $\begin{array}{c}\text { C. Sempronius Ge[min] } \\
\text { us, C. Sempronius } \\
\text { Car[p]us, C. Sempronius } \\
\text { Gracilis, C. Sempronius } \\
\text { Maur[us], C. Sempronius } \\
\text { Syneros y C. Sempronius } \\
\text { Fidens }\end{array}$ & Trajano \\
\hline CIL II 3002 & Osca & Victoria Aug(usti) & $\begin{array}{l}\text { L. Cornelius Phoebus y } \\
\text { L. Sergius Quintillus }\end{array}$ & Siglo II d.C. \\
\hline
\end{tabular}

Figura 16. Relación de consagraciones a la Victoria procedentes de Hispania Citerior. 


\begin{tabular}{|c|c|c|c|c|}
\hline Referencia & Lugar & Teónimo & Promotor & Cronología \\
\hline CIL II 864 & Vrunia & Victoria & $\begin{array}{l}\text { L. Marcius [Ma]xi[mus] } \\
\text { Gal. }\end{array}$ & Tiberio \\
\hline EE VIII, 14 & $\begin{array}{c}\text { Fundao (Castelo } \\
\text { Branco) }\end{array}$ & Victoria & [T]oncius [T]oncetamif. & Julio-Claudios \\
\hline CIL II 402 & Elbocoris & Victoria & C. Cantius Modestinus & Flavios \\
\hline AE 1996, 845 & $\begin{array}{l}\text { Povoa da Atalaia } \\
\text { (Castelo Branco) }\end{array}$ & Victoria & Curius Priuatus & Siglo I d. C. \\
\hline CIL II $5245=$ BE 4 & Elbocoris & $\begin{array}{c}\text { Vic [toria] Ae[terna] } \\
\text { (?) }\end{array}$ & - & Siglo II d.C. \\
\hline CILCC I, 279 & $\begin{array}{c}\text { Salvatierra de } \\
\text { Santiago (Cáceres) }\end{array}$ & Victoria & C. Iul. Iulianus & Siglos II-III d.C. \\
\hline García 1984, nº 16 & $\begin{array}{c}\text { Zebreira } \\
\text { (Castelo Branco) }\end{array}$ & Victoria & Aprodisia Clare 1. & Siglos II-III d.C. \\
\hline CILCC I, 25 & Alcántara (Cáceres) & Victoria & Balaesu(s) Cileae & Siglos II-III d.C. \\
\hline $\begin{array}{l}\text { Hernández Guerra } \\
\text { 2001, n' } 5\end{array}$ & Lerilla (Salamanca) & Victoria & Boutius Ambati & Siglos II-III d.C. \\
\hline HEp 2, 774 & Igaedis & Victoria & Maurio Marcif. & Desconocida \\
\hline CIL II 457 & $\begin{array}{l}\text { Santo Estevão } \\
\text { (Guarda) }\end{array}$ & Victoria & RufusTanginif. & Desconocida \\
\hline $\begin{array}{c}\text { CIL II } 927=\text { HEp } \\
5,258\end{array}$ & Augustobriga & Vic(toria) sac(rum) & Lucius Marci [f. (?)] & Desconocida \\
\hline HEp 5, 259 & Augustobriga & Vic(toria) sac(rum) & Lucius Marci [f.(?)]. & Desconocida \\
\hline AE 1960, 189 & Torre (Guarda) & Victoria & Sunua Tongif. & Desconocida \\
\hline HAEpigr. 1072 & Igaedis & Victoria & $F[---]$ & Desconocida \\
\hline AE 1979, 333 & Castelo Branco & Victoria & M.T.F. & Desconocida \\
\hline AE 1980, 549 & $\begin{array}{c}\text { Penamacor (Castelo } \\
\text { Branco) }\end{array}$ & Victoria & - & Desconocida \\
\hline $\begin{array}{c}\text { CIL II } 982=\text { ERBC } \\
90\end{array}$ & $\begin{array}{l}\text { Salvatierra de los } \\
\text { Barros (Badajoz) }\end{array}$ & $\begin{array}{l}\text { Victoria Aug(usta) } \\
\text { sacrum }\end{array}$ & $\begin{array}{c}\text { M. Terentius M. libertus } \\
\text { Ianuarius }\end{array}$ & Desconocida \\
\hline
\end{tabular}

Figura 17. Relación de consagraciones a la Victoria procedentes de Lvsitania.

\begin{tabular}{|c|c|c|c|c|}
\hline Referencia & Lugar & Teónimo & Promotor & Cronología \\
\hline $\begin{array}{c}\text { CIL II } 2327=\text { CILA } \\
\text { II, } 166\end{array}$ & Celti & Victoria Aug(usta) & $\begin{array}{c}\text { Atticus G. Fabi Nigri l. y } \\
\text { Firmo Bit(h)ynitis } l .\end{array}$ & Siglo I d.C. \\
\hline IRCadiz 513 & Arcilacis & Victoria sacrum & $\begin{array}{l}\text { C. Auielus C.f. Pap. } \\
\text { Paelignus }\end{array}$ & Siglo II d.C. \\
\hline $\begin{array}{c}\text { CIL II } 1425=\text { CIL } \\
\text { II }^{2} / 5,854\end{array}$ & Cortijo del Tajo & Victoria Aug(usta) & $\begin{array}{l}\text { Q. Fabius L.f. Gal } \\
\text { Fabullus }\end{array}$ & Siglo II d.C. \\
\hline CILA II, 358 & Italica & Vict(oria) Aug(usta) & $\begin{array}{l}\text { Vib. Modesta G. Vib. } \\
\text { Libonis fil. }\end{array}$ & Siglo II d.C. \\
\hline $\mathrm{CIL} \mathrm{II}^{2} / 5,367$ & Iponoba & Victoria Aug(usta) & M. Fabius Livianus & Siglos II-III d.C \\
\hline $\begin{array}{c}\text { CIL II } 5367=\text { CILA } \\
\text { II, } 359\end{array}$ & Italica & Victoria & - & Siglos II-III d.C \\
\hline CIL II 1967 & Malaca & Victoria Augusta & $\begin{array}{l}\text { L. Octavius L.f. Rusticus } \\
\text { y L. Granius M.f. Balbus }\end{array}$ & Desconocida \\
\hline CIL II 1346 & Acinipo & Victoria Aug(usta) & F. Proculus & Desconocida \\
\hline
\end{tabular}

Figura 18. Relación de consagraciones a la Victoria procedentes de Baetica. 
El cognomen Germulla constituye un hápax en la epigrafía peninsular, tanto en masculino como en femenino, si bien se ha encontrado atestiguado en otras partes del Imperio (Solin y Salomies 1994: 87) ${ }^{3}$. Se trata de una construcción realizada empleando el sufijo diminutivo -ullus, -ulla, quizá a partir del sustantivo germinis o bien germanus. A pesar de la ausencia de una relación directa entre las dos protagonistas del texto, la presencia del mismo nomen invita a considerar que podrían ser hermanas o, menos probable, madre e hija.

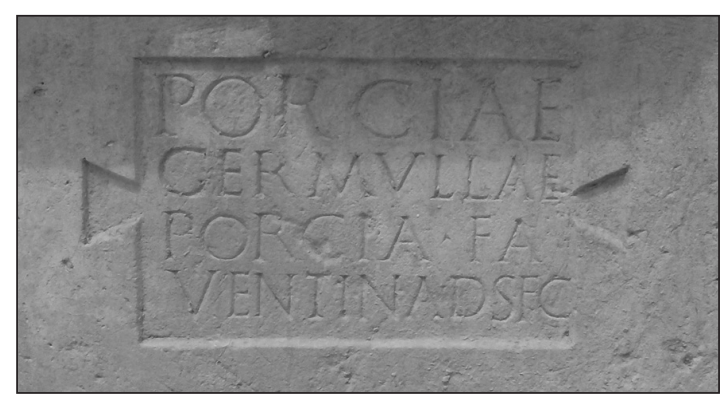

Figura 19. Inscripción no 4 (Foto: Á. A. Jordán).

5. Medidas: 82 x 94 x ? Campo epigráfico: 29,5 x 46. Letras: 6,5-3,5. Capital cuadrada. Interpunción triangular (Fig. 20).

L(ucio $) \cdot$ Fabio $\cdot$ Pla

cido $\cdot$ M(arcus $) \cdot$ Fabius

Nouus $\cdot$ patruo

$d(e) \cdot s($ uo $) \cdot f($ aciendum $) \cdot c$ (urauit)

En lín. 3 la $O$ final aparece con un tamaño mucho más pequeño, $3,5 \mathrm{~cm}$, como consecuencia de un error del quadratarius en la ordinatio del texto. Placidus constituye un cognomen común en la Península (Abascal 1994: 460-461). Este, como se indica en lín. 3, sería el tío paterno de M. Fabius Nouus una relación que no suele explicitarse demasiado en el conjunto epigráfico peninsular ${ }^{4}$.

\section{CONCLUSIÓN}

Se trata, como se puede ver, de un conjunto monumental compuesto por dos homenajes (n. 4 y 5),

\footnotetext{
${ }^{3}$ Así, por ejemplo, CIL VI, 14052: Cartoria Germulla de Roma, CIL IX, 3241: Anna T. l. Germulla de Corfinium e ILAlg 02-03, 10011 Sittia P. f. Germulla de Castellum Elefantum (Numidia).

${ }^{4}$ Así, por el momento se conocen tres casos: CIL II $2091=$ RIT $245=$ CIL II $^{2} / 14,1104$, de Tarraco; CIL II $4469=$ IRC II, 39 de Aeso y CIL II $2 / 5,875$ de Sabora, sobre la que pronto volveremos.
}

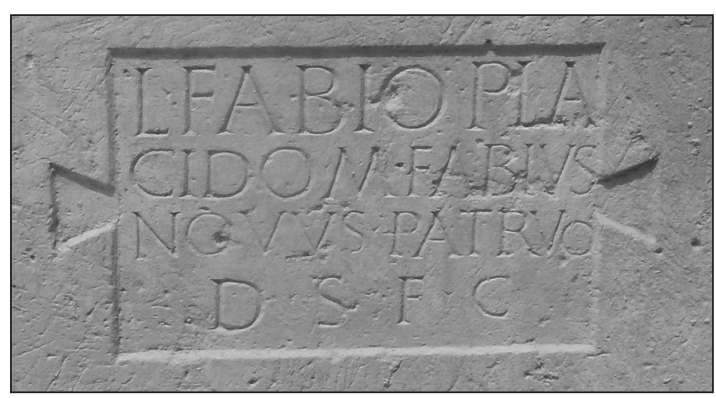

Figura 20. Inscripción nº 5 (Foto: Á. A. Jordán).

dos inscripciones auto-conmemorativas (n. 1 y 2) y una dedicatoria de carácter votivo (n. 3) que, dada su disposición en el eje de la estancia, servía para estructurar y centrar todo el ciclo. Este programa -de marcado carácter gentilicio (Navarro 2003; 2006)como informan los epígrafes, fue promovido por dos individuos de la elite local por más que no se aluda en ellos a su cursus honorum: M. Fabius Nouus y Porcia Fauentina, quienes aparecen autorepresentados en los textos 1 y 2 . Para ello, ambos optaron por emplazar, posiblemente, dos estatuas pedestres, a juzgar por los anclajes conservados. La de M. Fabius Nouus tal vez pudo estar en posición dinámica, andante, con la pierna izquierda adelantada. Por su parte, la de Porcia Fauentina muestra las cunas mucho más cercanas una de la otra, por lo que no se puede descartar que estuviera en actitud estática. Los textos, a juzgar por los caracteres paleográficos, pueden datarse en el siglo I d.C., posiblemente en época julio-claudia. En relación con ello, conviene subrayar que las excavaciones en el foro de Los Bañales están desvelando un primer momento constructivo del conjunto datado en época augustea — coincidiendo con la apertura de la vía al pie de la ciudad en ese mismo momento, a tenor de la información de los miliarios (IRMN 1 y 2 de Castiliscar y ERZ 19 de Ejea de los Caballeros) — que pronto fue reformado, posiblemente no más tarde de mediados del siglo I d. C. (Andreu et alii en prensa). Verosímilmente, la proximidad de este espacio a otros tres recintos contiguos — dos de ellos sin restos epigráficos y, el tercero, con cuatro pedestales de naturaleza votiva (Jordán 2012) promovidos por una notable local, Pomp (eia) Paulla - permite suponer que —al igual que sucede en los foros hispanos de Segobriga (Abascal et alii 2002) o de Pollentia (Chavez et alii 2010), por ejemplo- las tabernae y los sacella de los pórticos forenses fueron empleados como espacios de naturaleza a medio camino entre la religión —en el caso del recinto que nos ocupa, seguramente, el culto imperial- y la auto-representación pública de sus promotores, una combinación de usos del espacio 
para la que, desde luego, tenemos otros ejemplos en la epigrafía forense hispana (Jordán y Andreu 2013) y, como se verá, también de Occidente. Aquéllos obtenían permiso del ordo para la construcción de esos espacios en aras de su finalidad cultual y de su carácter de ornamenta rei publicae, permiso que, naturalmente, ellos empleaban para mostrarse ante la sociedad en un espacio neurálgico de la vida cívica romana. En este sentido no hace mucho que los trabajos realizados en el foro de Avenches (Suiza), solar de la antigua Auenticum, han dado con una serie de estructuras rectangulares ubicadas en espacios inmediatos al foro y abiertas a su plaza pública que han sido interpretadas como scholae, en cualquier caso, como recintos auto-representativos propiedad de varias familias de notables (Goffaux 2010: 7 y 22) lo que, desde luego, podría dar razón de ser a la sucesión de dos recintos asociados a destacadas familias - las Pompeiae, los Fabii y las Porciae- en el pórtico occidental del foro de Los Bañales (Jordán y Andreu 2013; Andreu et alii en prensa).

Con este conjunto estatuario familiar los autores, en el fondo, estaban copiando los programas dinásticos que los emperadores plasmaron en los foros de las ciudades del Imperio y, en ocasiones, en augusteia, en una práctica mimética común entre las élites locales (Zanker 1992; Abascal 1996; Abascal et alii 2002: 136-137; Navarro 2006; Melchor 2009: 445-446). Su desarrollo llevó a la realización de frecuentes homenajes y, especialmente, al desarrollo de la auto-representación ${ }^{5}$ y, en ocasiones, desembocaron, al igual que hicieron los emperadores, en la realización de grandes ciclos estatuarios como el que nos ocupa, dispuestos en espacios semipúblicos fruto de los comportamientos munificentes de estos notables (Melchor 1993: 443-445; Jordán y Andreu 2013) y con un especial protagonismo, además, de las mujeres (Melchor 2009 y 2010; Navarro 2006). Así, otro ejemplo similar al hallado en Los Bañales es el encontrado, por desgracia, descontextualizado, en el cortijo de Fuentepeones (Cañete la Real), solar de la antigua Sabora. Se trata de tres inscripciones financiadas por M. Pupius Caldus. La primera corresponde

\footnotetext{
${ }^{5}$ El estudio de la auto-representación -Selbstdarstellung, self-representation- ha dado lugar a múltiples trabajos y coloquios emplazados desde ópticas distintas. Son ya clásicos los coloquios dirigidos por M. Cébeillac-Gervasoni sobre las elites, de entre los que se puede destacar el último, expresamente centrado en la autorrepresentación (CébeillacGervasoni et alii 2004). Junto a ellos destacan los trabajos particulares de Feraudi-Gruénais 2003, que analiza este fenómeno desde el punto de vista de la epigrafía funeraria, los de H. Wrede (Wrede 1981) y A. Sartori (Sartori 1993,2000; 2003), quienes se centran en la epigrafía sacra y, por supuesto, los de G. Alföldy (Alföldy 1999, 2004).
}

al fragmento de un pedestal de caliza consagrado a la Fortuna. El segundo texto es otro pedestal calcáreo realizado en honor de una desconocida [---]lia C. $f$. [---]na, auia paterna de M. Pupius Caldus, mientras que el último está dedicado a su tío paterno, por desgracia de nombre desconocido ${ }^{6}$.

Nos parece que otro conjunto con una vocación mimética similar es el hallado en Labitolosa, y realizado por dos promotores: M. Clodius Flaccus y Cornelia Neilla (Navarro et alii 1995; Jordán 200405: 369-373; Navarro y Magallón 2013). El primero financió una estatua del Genio del municipio, que se emplazó jerarquizando la cella del templo, mientras que Cornelia Neilla dispuso por testamento la realización de un conjunto de estatuas de allegados suyos, situadas en el perímetro. Esta tarea recayó en dos curatores: Cornelius Philemon, quizá un liberto, y Clodia [-], bien una liberta de la evergeta o bien una familiar (¿hija?), y fueron homenajeados el hijo de ambos, M. Clodius M. f. Gal. Flaccus, la propia Cornelia Neilla, L. Aemilius Attaeso y un desconocido L. Ae[milius] L. f. [---].

Para finalizar, la presencia de estos textos in situ permite aventurar un contexto para conjuntos similares que, debido al paso del tiempo, han llegado descontextualizados y constituyen interrogantes dentro del panorama epigráfico peninsular. Un ejemplo de esta situación pueden ser los dos tituli realizados por $G$. Sulpicius Africanus encontrados en Ujo (Asturias), durante las obras de construcción de la estación de ferrocarril. El primero se trata de un homenaje al caballero G. Sulpicius Ursulus, sin duda, familiar de G. Sulpicius Africanus, aunque se desconoce en qué grado. Por otro lado, el segundo texto corresponde a un altar consagrado a Nimmedo Seddiago ${ }^{7}$. En ellos de nuevo se reconoce la presencia de una estructuración similar, encabezada por una inscripción cultual que, posiblemente, daba razón de ser al conjunto, tal vez ofreciendo la excusa necesaria para la ocupación del espacio público. Junto a ella, varios homenajes, en este caso uno que, puesto que presenta el nombre del promotor abreviado, quizá estuvo subordinado al primer texto, que informaba claramente de éste.

Se trata, en conclusión, de un descubrimiento epigráfico excepcional que contribuye a mejorar nuestro conocimiento tanto de la sociedad del desconocido

\footnotetext{
${ }^{6} \mathrm{CIL} \mathrm{II}^{2} / 5,872:$ Fortuna[e Aug(ustae?)] / M(arcus) $\cdot$ Pupius C[aldus] / dedit. CIL II'2/5, 873: + [-ca. 3-]+liae - C(ai) . f(iliae) $\cdot+[$-ca.3-]/nae auiae $\cdot$ pa/ternae $\cdot M($ arcus $) P[u] /$ pius Cald[us] / dedit. CIL II ${ }^{2} / 5$, 875: --- / M(arco) · Pupi[o Qu] ieto / patruo.

7 ERAS 22, uid. las prevenciones al respecto de esta inscripción en Jiménez de Furundarena y Rodríguez González 1991. ERAS 9.
} 
municipio de Los Bañales como, especialmente, de la disposición epigráfica general, permitiendo identificar formas mucho más complejas de auto-publicitación de la elite local y ofreciendo un espejo ante el cual poder poner textos que han llegado hasta la actualidad descontextualizados o aislados.

\section{BIBLIOGRAFÍA}

Abascal, J. M. 1994: Los nombres personales en las inscripciones latinas de Hispania, Murcia.

Abascal, J. M. 1996: "Programas epigráficos augústeos en Hispania", Anales de Arqueología Cordobesa 7, 45-82.

Abascal, J. M., Almagro Gorbea, M., y Cebrián, R. 2002: "Segobriga 1989-2000. Topografía de la ciudad y trabajos en el foro", Madrider Mitteilungen 43, 123-161.

Abascal, J. M. y Ramallo, S. 1997: La ciudad de Carthago Nova: la documentación epigráfica, Murcia.

Aguarod, C. y Lostal, J. 1982: "La vía romana de las Cinco Villas”, Caesaraugusta 55-56, 167-218.

Alföldy, G. 1999: "La cultura epigráfica de la Hispania romana: inscripciones, auto-representación y orden social", M. Almagro-Gorbea y J. Ma Álvarez Martínez (eds.), Hispania. El legado de Roma, Zaragoza, 324-337.

Alföldy, G. 2004: “Die Repräsentation der kaiserlichen Macht in den Inschriften Roms und des Imperiums Romanum", L. De Blois, P. Erdkamp, O. Hekster, G. de Kleijn y St. Mols (eds.), The Representation and Perception of Roman Imperial Power. Proceedings of the third Workshop of the International Network Impact of Empire (Roman Empire, c. 200 BC-AD 476), Amsterdam, 3-19.

Andreu, J. 2011: "La ciudad romana de Los Bañales (Uncastillo, Zaragoza) en las fuentes históricas", J. Andreu (ed.), La ciudad romana de Los Bañales (Uncastillo, Zaragoza): entre la historia, la arqueología y la historiografía, Caesaraugusta 82, Zaragoza, 19-200.

Andreu, J. 2012: La ciudad romana de Los Bañales. Uncastillo - Zaragoza. Guía histórico-arqueológica, Zaragoza.

Andreu, J. 2013: "Sobre un repertorio de objetos de hueso romanos del Norte de la Tarraconense: Los Bañales de Uncastillo (Zaragoza, España)", Habis 44, 115-140.

Andreu, J. 2014: "Movilidad de personas y relaciones entre ciudades en época romana en el conventus de Caesar Augusta: aspectos epigráficos y prosopográficos", Veleia 30, 75-93.

Andreu, J., y Jordán, Á. A. 2003-04: "Epigrafía, orga- nización del territorio y poblamiento en territorio de Vascones: Los Bañales (Uncastillo, Zaragoza)", Espacio, Tiempo y Forma. Serie 1. Prehistoria y Arqueología 16-17, 419-461.

Andreu, J., Bienes, J. J., y Jordán, Á. A. en prensa: "Monumentalización y regresión urbanas en un municipio Flavio del norte del convento jurídico Cesaraugustano: Los Bañales de Uncastillo", A. Quevedo (ed.), ¿Crisis urbana a finales del Alto Imperio. La evolución de los espacios cívicos en el Occidente Romano en tiempos de cambio (siglos. $I I-I V$ d. C.), Murcia.

Andreu, J., Bienes, J. J., Lasaosa, E., y Romero, L. en prensa: "El foro de la ciudad romana de Los Bañales (Uncastillo, Zaragoza): aspectos estructurales y cronológicos preliminares", Actas del XVIII Congreso Internacional de Arqueología Clásica, Mérida.

Andreu, J., González Soutelo, S., García-Entero, V., Jordán, Á. A. y Lasuén, M. 2008: "Cuestiones urbanísticas en torno a la ciuitas de los Bañales (Uncastillo, Zaragoza)", SPAL. Revista de Prehistoria y Arqueología de la Universidad de Sevilla 17, 233-266.

Cébeillac-Gervasoni, G., Lamoine, L. y Trement, Fr. (eds.) 2004: Autocélébration des élites locales dans le monde romain. Contextes, images, textes (IIe segle. av. J.C. I IIIe segle. ap. J.C.), Clermont-Ferrand.

Chavez, M. E., Orfila, M., y Cau, M. A. 2010: “El foro de Pollentia (Alcudia-Mallorca, España). Descubrimientos recientes", Bolletino di Archeologia on line 1, 1-7.

Etienne, R. 1958: Le culte impérial dans la Péninsule Ibérique d'Auguste a Dioclétien, Paris.

Fernandes, L. 2002: "As virtutes. Seu culto e representação no âmbito da província da Lusitânia", Religiões da Lusitânia. Loquuntur saxa, Lisboa, 165-174.

Feraudi-Gruénais, F. 2003: Inschriften und 'Selbstdarstellung' in stadtrömischen Grabbauten, Roma.

Fischwick, D. 1987: The imperial Culti in the Latin West. Studies on the Ruler cult of the western provinces of the Roman Empire, Leiden.

García, J. M. 1984: Epigrafía lusitano-romana do Museu Tavares Proença Junior, Castelo Branco.

Giuliani, C. F. 1997: "L'opus caementicium nell'edilizia romana", Materiali e Strutture 2-3, 49-62.

Goffaux, B. 2010: "Scholae et espace civique à Avenches", Bulletin de l'Association Pro Aventico 52, 7-26.

Hernández Guerra, L. 2001: Epigrafía de época romana de la provincia de Salamanca, Valladolid. 
Jiménez de Furundarena, A., y Rodríguez González, J. 1991: "La lápida de Gayo Sulpicio Ursulo: ¿una falsificación de época?", Hispania Antiqua $15,83-90$.

Jordán, Á. A. 2012: "Una donación ex testamento procedente del foro de Los Bañales (Uncastillo, Zaragoza)", Espacio, Tiempo y Forma. Serie 2. Historia Antigua 25, 75-92.

Jordán, Á. A. 2009: "Ritmos epigráficos en el área nororiental del solar vascón: las Cinco Villas de Aragón", J. Andreu (ed.), Los Vascones de las fuentes antiguas. En torno a una etnia de la Antigüedad Peninsular, Barcelona, 513-526.

Jordán, Á. A. 2004-05: "Curia ordinis. Uso epigráfico de un edificio singular", Espacio, tiempo y Forma. Serie 2. Historia Antigua 17-18, 361-373.

Jordán, Á. A. y Andreu, J. 2013: "La presencia privada en los foros hispanos a la luz de dos programas epigráficos hallados in situ en Los Bañales (Uncastillo, Zaragoza)", A. Ruiz y J. M. Iglesias (eds.), Paisajes Epigráficos de la Hispania Romana: monumentos, contextos, topografías, Santander, 127-143.

Kajanto, I. 1965: The Latin Cognomia, Helsinki.

Magallón, M. A. 1986: "La red viaria romana en las Cinco Villas", Actas de las I Jornadas de Estudio sobre las Cinco Villas (Ejea, diciembre 1985), Zaragoza, 95-143.

Melchor, E. 1993: "Construcciones públicas y evergetismo en Hispania Romana", Espacio, tiempo y Forma. Serie 2. Historia Antigua 6, 443-466.

Melchor, E. 2010: "Homenajes estatuarios e integración de la mujer en la vida pública municipal de las ciudades de la Bética", F. J. Navarro (ed.), Pluralidad e ntegración en el mundo romano, Pamplona, 221-245.

Moreno, I. 2009: Item a Caesarea Augusta Beneharno. La carretera romana de Zaragoza al Bearn, Ejea de los Caballeros.

Navarro, M. 2003: "Mujer de notable: representación y poder en las ciudades de la Hispania imperial", S. Armani, A. U. Stylow y B. Hurlet-Martineau (eds.), Epigrafía y sociedad en Hispania durante el Alto Imperio: estructuras y relaciones sociales, Alcalá de Henares/Madrid, 119-127.

Navarro, M. 2006: "Famille impériale et dynasties locales: un modèle idéologique reproduit dans les cités hispaniques sous l'Empire", M. Navarro y J.
M. Roddaz (eds.), La transmission de l'ideologie impériale dans les provinces romaines, Burdeos, 69-84.

Navarro, M., y Magallón, Má Á. 2013: "Epigrafía y sociedad de Labitolosa", M ${ }^{\mathrm{a}}$ Á. Magallón y P. Sillières (eds.), Labitolosa, una cité romaine de l'Hispanie Citérieure, Bordeaux, 334-400.

Navarro, M., Sillières, P., y Magallón, M. A. 1995: "El Municipium Labitulosanum y sus notables: novedades arqueológicas y epigráficas", Archivo Español de Arqueología 68, 107-130.

Olteanu, T. 2008: "El culto a la victoria y la interpretatio indígena en el occidente de Hispania, Galia y el Norte de Britania", Boletín del Seminario de Arte y Arqueología 74, 197-224.

Perea, S. 2007: "El culto a la Victoria Augusta en Roma y en la Hispania altoimperial", L. Hernández Guerra (ed.), El mundo religioso hispano bajo el imperio romano. Pervivencias y cambios, Valladolid, 221-235.

Sartori, A. 1993: "Epigrafia sacra e appariscenza sociale", Religio Deorum. Actas del Coloquio Internacional de Epigrafía A.I.E.G.L. Culto y sociedad en Occidente, Sabadell, 423-434.

Sartori, A. 2000: Gente di Sasso. Parlano gli antichi milanesi, Milano.

Sartori, A. 2003: "La promozione del consenso: autorappresentazione e modelli epigrafici nelle comunità municipali cisalpine", C. Castillo, J. F. Rodríguez Neila y F. J. Navarro, (eds.), Sociedad y economía en el occidente romano, Pamplona, 283-308.

Solin, H. y Salomies, O. 1994: Repertorium nominum gentilium et cognominum Latinorum, HildesheimNew York.

Uribe, P., Hernández Vera, J. A. y Bienes, P. 2011: “La edilicia urbana privada en Los Bañales: estado de la cuestión", J. Andreu (ed.), La ciudad romana de Los Bañales (Uncastillo, Zaragoza): entre la historia, la arqueología y la historiografía, Caesaraugusta 82, Zaragoza, 241-260.

Wrede, H. 1981: Consecratio in formam deorum. Vergöttlichte Privatpersonen in der römischen Kaiserzeit, Mainz am Rhein.

Zanker, P. 1992: Augusto y el poder de las imágenes, Madrid.

Recibido: 26-09-2013

Aceptado: 15-01-2014 